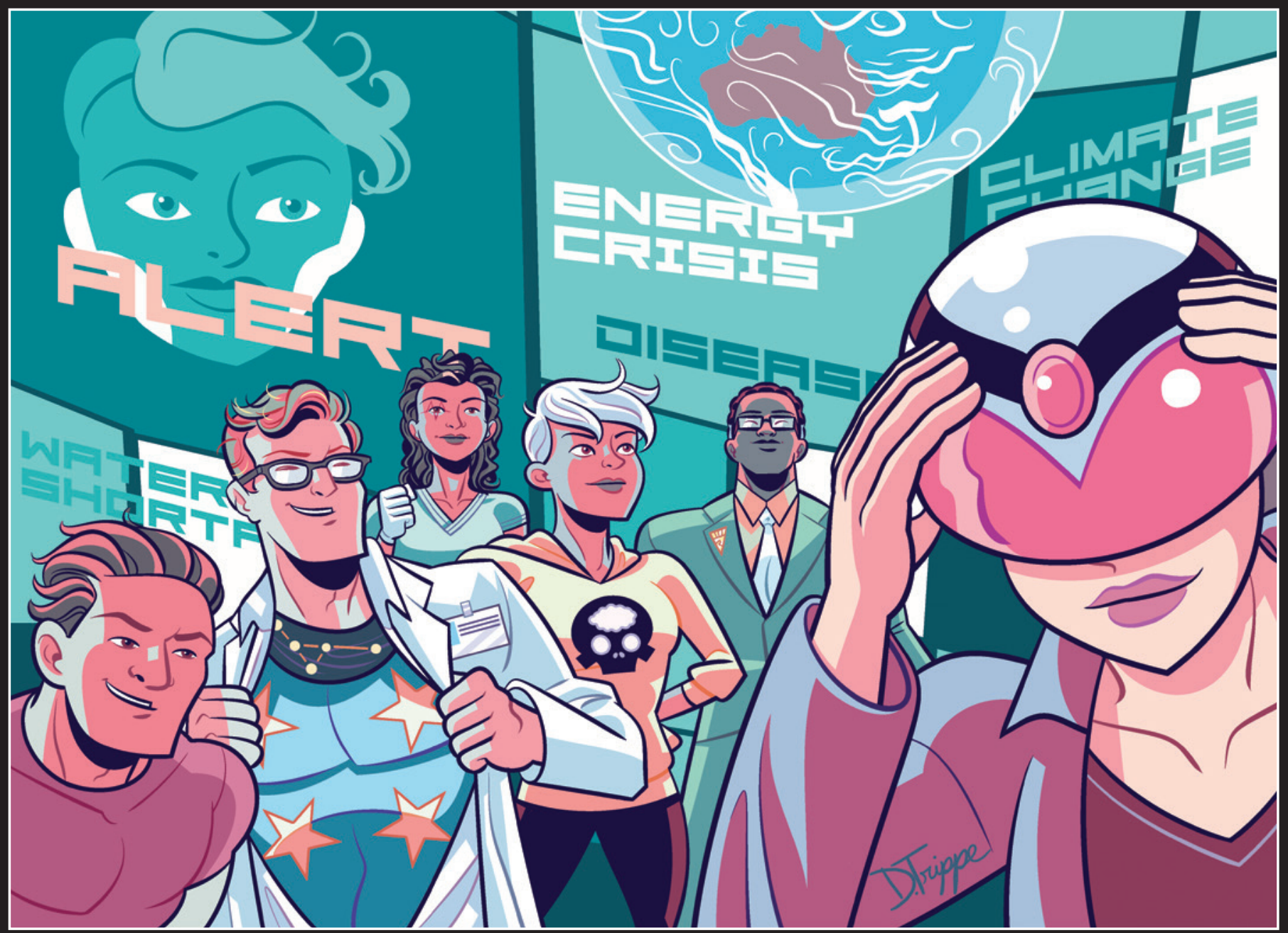

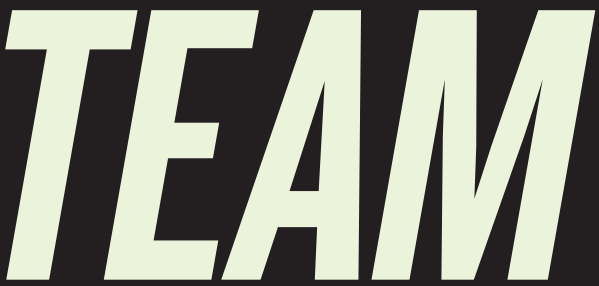

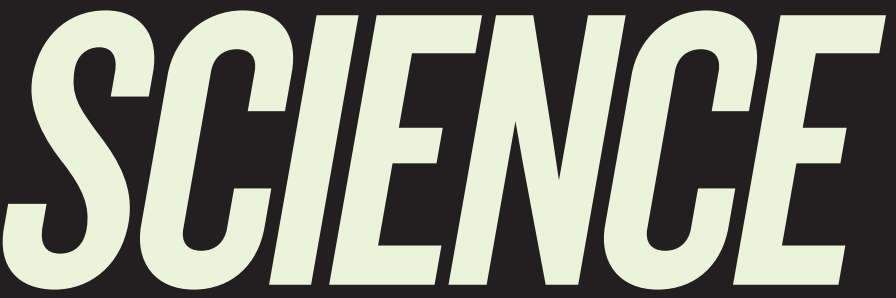

Interdisciplinarity has become all the rage as scientists tackle society's biggest problems. But there is still strong resistance to crossing borders.

BY HEIDI LEDFORD

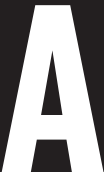
sking for US\$40 million is never easy, but Theodore Brown knew his pitch would be a particularly tough $\frac{0}{\underline{\underline{x}}}$ sell. As vice-chancellor for research at the University of Illinois at Urbana-Champaign in the early 1980s, Brown had been tasked with soliciting a major donation from wealthy chemist and entrepreneur Arnold Beckman, a graduate of the university. Beckman was hesitant, believing that the university should receive most of its support from the state. So Brown decided to devise a project like nothing he had ever seen before.

In 1983, he and his colleagues put together a proposal for an institute that had little chance of being funded through normal channels. It would defy the powerful disciplinary cartography that defines many modern universities, bringing together members of different departments and inducing them to work together on common projects. Brown argued that it would allow faculty members to tackle bigger scientific and societal questions than they normally could.

"The problems challenging us today, the ones really worth working on, are complex, require sophisticated equipment and intellectual tools, and just don't yield to a narrow approach," he says. "The traditional structure of university departments and colleges was not conducive to cooperative, interdisciplinary work."

It was an early example of the push for interdisciplinary research that is now sweeping universities around the globe. Although Brown was not completely alone - the interdisciplinary Santa Fe Institute in New Mexico was founded around the same time - he was advocating crossing boundaries before it 
became fashionable. And his proposal met strong resistance. Department heads fretted that faculty members - and their grants - would be snatched away. Some colleagues scorned Brown's idea of creating open office spaces to foster interactions between graduate students: surely the din would make it impossible to get serious work done. And then there was the stigma. "Interdisciplinary research is for people who aren't good enough to make it in their own field," an illustrious physicist chided.

But Beckman liked the idea and committed the full $\$ 40$-million asking price - at that time, the largest-ever private donation to a US public university. A few hectic years later, the 29,000-square-metre Beckman Institute for Advanced Science and Technology was born.

The institute struggled to recruit a qualified director willing to take a chance on the new model, so Brown took the helm. Soon, large grants from organizations such as the Department of Defense and the National Science Foundation poured in, hushing many critics. By the time Brown left the institute in 1993, other leading universities were sending delegations there to learn from the model. Researchers from Beckman - which now has more than 200 affiliated faculty members - have achieved attention-grabbing results, including helping to create one of the first graphical web browsers.

Since the Beckman was founded, the interdisciplinary model has spread around the world, countering the trend towards specialization that had dominated science since the Second World War. Cross-cutting institutes have sprouted up in the United States, Europe, Japan, China and Australia, among other places, as researchers seek to solve complex problems such as climate change, sustainability and publichealth issues. The interdisciplinary trend can be seen in publication data, where more than one-third of the references in scientific papers now point to other disciplines (see page 306 ). "The problems in the world are not within-discipline problems," says Sharon Derry, an educational psychologist at the University of North Carolina at Chapel Hill who studies interdisciplinarity. "We have to bring people with different kinds of skills and expertise together. No one has everything that's needed to deal with the issues that we're facing."

Even so, supporters of interdisciplinary research say that it has been slow to catch on, and those who do cross academic disciplines face major challenges when applying for grants, seeking promotions or submitting papers to high-impact journals. In many cases, scientists say, the trend is nothing more than a fashionable label. "There's a huge push to call your work interdisciplinary," says David Wood, a bioengineer at the University of Minnesota in Minneapolis. "But there's still resistance to doing actual interdisciplinary science."

\section{HIGHLY DISCIPLINED}

The idea of dividing academic inquiry into discrete categories dates back to Plato and Aristotle, but by the sixteenth century, Francis Bacon and other philosophers were mourning the fragmentation of knowledge.

One problem lay in the rapid growth of science: there was too much information spread across the disciplines for any one person to handle. Science historian Peter Weingart of Bielefeld University in Germany points to Carl Linnaeus's taxonomic treatise Systema Naturae as an example: between its first edition in 1735 and its last in 1768 , the catalogue swelled from 10 pages to 2,300 , covering 7,000 species.

In the nineteenth century, the disciplinary boundaries of the modern university started to take root. The disciplines surged in number and power after the Second World War, as nations, particularly the United States, boosted their research support. "It's the moment when universities increased exponentially," says Vincent Larivière, an information scientist at the University of Montreal in Canada. "And the size of the university increased by creating more departments."

Tensions between the United States and the Soviet Union also played a part, says Weingart. The Soviets boasted a research programme geared towards solving societal problems, for example improving agriculture to boost food security. By contrast, US President Dwight Eisenhower argued that basic research should be untethered. "In the field of intellectual exploration, true freedom can and must be practised," he said in a 1959 speech. And although basic research need not necessarily be disciplinary, it does not have the same pressure towards interdisciplinarity as does applied research.

\section{"WE HAVE TO BRING PEOPIE WITH DIFFERENT KINDS OF SKILLS AND EXPERTISE TOGETHER. NO ONE HAS EVERYTHNG THAT'SNEEDED."}

Specialities proliferated as individual disciplines were repeatedly subdivided. Biology was split into botany and zoology, then into evolutionary biology, molecular biology, microbiology, biochemistry, biophysics, bioengineering and more. Late last year, Jerry Jacobs, a sociologist at the University of Pennsylvania in Philadelphia, counted the number of biology-related departments at Michigan State University in East Lansing. There were nearly 40.

From this thicket, the term 'interdisciplinary' emerged. The earliest citation in the Oxford English Dictionary dates back to December 1937, in a sociology journal. But even at that time, some believed that the word was already overused. In a report to the US Social Science Research Council in August that year, a sociologist at the University of Chicago in Illinois lumped 'interdisciplinarity' in with other "catch phrases and slogans which were not sufficiently critically examined" (R. Frank Items 40, 73-78; 1988).

As an academic movement, interdisciplinarity caught on during the 1970s and has been growing ever since, says Larivière. He credits that rise in part to libraries, which began to stockpile subscriptions and improved researchers' access to journals in alternative fields. A particle physicist could more easily browse biology journals, say. Furthermore, the US focus began to shift from basic research and scientific liberty back to societal problems such as environmental protection, which can rarely be tackled by a single discipline.

The United States was not alone: in 1994, an influential book partially sponsored by the Swedish Council for Planning and Coordination of Research called The New Production of Knowledge (Sage) predicted, among other things,

\begin{tabular}{|l|l|}
\hline Af & INTERDISCIPLINARITY \\
& $\begin{array}{l}\text { A Nature special issue } \\
\text { nature.com/inter }\end{array}$ \\
\hline
\end{tabular}
an increasingly interdisciplinary future as science seeks to solve socially relevant questions. That book had an impact, says Larivière, particularly in the European 
Union's Fifth Framework funding programme, which ran from 1998 to 2002 and emphasized interdisciplinary, problem-oriented research.

Soon, interdisciplinary institutes began to sprout up around the world, each with its own unique structure and purpose. One of the first, the Santa Fe Institute, founded in 1984, focused on applying advanced mathematics and computational skills to a range of disciplines. Others, such as

\section{"THEREIS CONSTANT PRESSURE ON ME TO MAKE A CROSS-FACUITY, CROSS-NSSTIIUTIONALLLANCE. IFI WANT TO BUILD A NEW BUILDING, THE MORE ALLIIES IHAVE, THE EASIER ITISTO RAISE THE MONEY."}

the Massachusetts Institute of Technology's David H. Koch Institute for Integrative Cancer Research in Cambridge, or the neuroscience-focused Janelia Research Campus in Ashburn, Virginia, tackle questions within a specific discipline but draw in work from other fields. And some, such as the Monash Sustainability Institute in Clayton, Australia, focus on specific problems.

Even as the trend gained momentum, interdisciplinary researchers continued to hit the same hurdles that Brown had encountered. In 1998, chemist Richard Zare at Stanford University in California helped to launch the interdisciplinary institute Bio-X. But an influential colleague urged him not to move his lab into the Bio-X building. Doing so would essentially take Zare away from the chemistry department and his committee and teaching duties there, the colleague argued, weakening the department.

Although he was well established, Zare worried about going against the establishment. "It was very serious," he says. The risk is even greater for young professors seeking tenure, he notes.

In 2004, in response to the growing interest in interdisciplinary work - and the challenges that face those who attempt it - the US National Academies released a report called Facilitating Interdisciplinary Research. The authors advised institutions to lower barriers, for example by making budgets flexible so that costs could be shared across departments.

The publication drew a large audience. It has been downloaded more than 7,600 times and had impact beyond US shores. At Durham University, UK, says physicist Tom McLeish, administrators referred to the report when they were forging a series of on-campus interdisciplinary centres. Around that time, McLeish was serving as pro-vice-chancellor of research, and saw interdisciplinarity as a way to make the small university shine on the world stage. He battled with department chairs who feared that the centres would reduce their budgets, and he worked to set up a promotion system that rewards investigators on large team grants in the same way as those on single-investigator grants. The university now has interdisciplinary centres on topics ranging from resilience - both ecological and psychological - to the history of medieval science.

The interdisciplinary trend is also growing in Asia. In 2000, the National Natural Science Foundation of China (NSFC) laid out a plan for interdisciplinary research, and universities have launched several cross-cutting centres over the past decade, including the Academy for Advanced Interdisciplinary Studies at Peking University in Beijing. The NSFC plans to launch further interdisciplinary projects in the coming years, says Yonghe Zheng, deputy director-general of the foundation's Bureau of Science Policy. "China is a developing country," he says. "So the universities and institutes can quickly set up some new centres which reflect the new trend in interdisciplinary research."

Nanyang Technological University in Singapore established its Interdisciplinary Graduate School in 2012; it already has 335 students, out of a total graduate-school population of 2,000. Nanyang's interdisciplinary graduate programme, which bills itself as the first of its kind in Asia, was designed in part to expand the university's fundraising options, says Bo Liedberg, dean of the programme. Because industry is often focused on real-world problems that cross disciplines, an interdisciplinary programme could foster more collaborations with business, he reasons.

That focus on interdisciplinarity as a revenue stream is widespread, says Merlin Crossley, a molecular biologist and dean of the faculty of life sciences at the University of New South Wales in Sydney, Australia. "There is constant pressure on me to make a cross-faculty, cross-institution alliance," he says. "If I want to build a new building, the more allies I have, the easier it is to raise the money." Arizona State University in Tempe saw its federal funding rise by $162 \%$ from 2003 to 2012 as it promoted interdisciplinarity across its campus (see Nature 514, 292-294; 2014).

Despite this pressure, interdisciplinarity's reach remains modest. For every Nanyang or Durham, there are hundreds of universities that have not embraced significant change. Departmental dividers remain in place - and in power - at most institutions, says Nancy Andreasen, a neuroscientist at the University of Iowa in Iowa City who co-chaired the committee that wrote the National Academies report more than a decade ago. "It has been an enormous disappointment."

\section{TEAM WORK}

For institutions or programmes that have embraced interdisciplinarity, the transition has not always been easy. The most common mistake is underestimating the depth of commitment and personal relationships needed for a successful interdisciplinary project, says Laura Meagher, a consultant based near St Andrews, UK, who coaches interdisciplinary teams. "You see people who think it's not much more than stapling a bunch of CVs to the back of a proposal," she says. "They don't realize that it takes time to build a relationship."

When the push for collaboration comes from the top, some of that focus on personal relationships could be lost - leaving the project to suffer, she says. The UK Energy Research Centre (UKERC) in London, which since 2004 has coordinated and carried out sustainable-energy research, learned how delicate interdisciplinary relationships can be, says Mark Winskel, a social and political scientist at the University of Edinburgh who evaluated the centre's first decade. Its initial five-year phase went well, he says, and culminated in a key publication: Energy 2050, which synthesized the institution's results and translated them into recommendations. But the next five-year phase failed to produce a similar achievement.

Winskel surveyed members and found that changes in the UKERC's structure designed to open it to a wider community - for example by offering several rounds of fresh grants 
in the middle of phase two - had upset some established long-term relationships. "We became a more diverse community of scholars and disciplines," he says. "But that also means you become less cohesive." The UKERC learned from the experience: its third phase, launched in May 2014, aims to provide more stability for collaborative relationships.

Social scientists in particular often face that lack of cohesion, says Thomas Heberlein, a social psychologist at the University of Wisconsin-Madison. When funders emphasize the societal impacts of the work they support, social scientists are often called in to assess the broader implications of a project. But, he says, it is obvious - and insulting - when a social scientist is asked to join a project as a way to tick a box, without a true commitment to incorporating the discipline into the project.

\section{SOCIAL STRUGGLE}

Several UK studies have found that social scientists are less likely than researchers in other disciplines to want to participate in interdisciplinary projects. For Heberlein, who has long collaborated with ecologists and environmental scientists, one of the stumbling blocks is what he calls "the hegemony of the natural sciences". Those disciplines tend to be held in higher esteem than more qualitative fields such as the social sciences, and they are deemed more rigorous by funders and researchers, he says. That imbalance leads to frustration and undermines collaboration. Heberlein, whose speciality is in conducting surveys of public opinions, says that natural scientists often naively suggest that they can design and execute surveys themselves using an Internet tool such as SurveyMonkey. Heberlein disagrees: "It's really hard to do the stuff we do," he says. "Our measurements are complicated."

Lack of respect can run in many directions when different kinds of researchers come together. Wood says that bioengineers are always cautioned against having their grants reviewed by panels of biologists, who may be dismissive of engineering research goals and measurements. But he has also served on review panels in which engineers have recoiled at the limitations of clinical research.

As more researchers become involved with interdisciplinary work, the mutual suspicion has started to ease. There have also been some signs of success in the funding arena. The US National Institutes of Health (NIH), for example, says that interdisciplinary proposals fare as well as, or slightly better than, more conventional applications. The European Research Council, by contrast, has noted that interdisciplinary grant proposals on average do not fare as well in review panels as projects that are narrower in scope.

The atmosphere for publishing is also mixed. Interdisciplinary researchers have long complained that it is difficult to get their papers into top-tier disciplinary journals. Heberlein says that the rise of interdisciplinary journals has helped in his field, but he worries about the standard of some of the papers they publish. And he questions the wisdom of training graduate students across disciplines before they have immersed themselves in the rigours of one area. "You've got to develop your disciplinary skills first," he says. "The bad news is the quality of this research is pretty bad and may be getting worse."

Many view the institutional push for interdisciplinarity as an experiment in progress. "The celebrations have begun, but the actual data on what kind of difference this makes are not in," says Scott Frickel, a sociologist at Brown
University in Providence, Rhode Island.

As more institutions adopt new ways to organize research, some are also trying to rethink their assessment processes, says McLeish. In July, Veronica Strang at Durham and McLeish released a report called Evaluating Interdisciplinary Research, and he was surprised when academic societies and funders flocked to learn more. "We didn't anticipate that we'd be launching this report into an atmosphere where everyone wants to know this," he says.

And the pace of change varies across the globe. In the United States, the NIH ran a programme to stimulate interdisciplinary research from 2004 to 2012. It resulted in some changes, such as starting to recognize multiple principal investigators on what had been considered single-investigator grants - a switch that removed a disincentive to collaborate. Since then, the agency has not perceived a need to follow up with any other incentives, noting that there are more than 4,000 active NIH-funded research projects that bill themselves as interdisciplinary. "Our general sense is that interdisciplinary research has become a very standard way of doing science," says Betsy Wilder, head of the NIH Office of Strategic Coordination. "It really pervades NIH funding."

In some other countries, the experiment has just begun. Chemist Ayyappanpillai Ajayaghosh, director of the National Institute for Interdisciplinary Science and Technology in Thiruvananthapuram, India, says that momentum is building in his country to promote more interdisciplinary projects. In

\section{"YOU SEE PEOPLE WHO THNNKIT'SNOT MUCH MORE THAN STAPLING A BUNCH OFCIS TO THE BACK OF A PROPOSAL. THEY OON'T REALIIE THATIT TAKES TIME TO BUILD A RELATIONSHIP."}

Japan, theoretical physicist Tetsuo Hatsuda left the University of Tokyo in part because he felt that the boundaries between disciplines were too heavily enforced there. In 2013, he joined the RIKEN research institute in Wako, Japan, and launched an interdisciplinary team of theoretical physicists, chemists and biologists to work out techniques that will accelerate all three fields. He hopes that the effort will stimulate more interdisciplinary work in the country. "Japan is a little behind other countries," he says. "Theoretical science is a good starting point because it is easy for us to interact."

Some 25 years after it opened, the Beckman Institute's experiment in interdisciplinary research has been a success, says Brown. The centre continues to attract distinguished faculty members and large team grants - last year it won a research contract worth up to $\$ 12.7$ million from the federal government's Intelligence Advanced Research Projects Activity programme - even though competition for such money has increased as more universities build interdisciplinary teams.

And Brown bristles at the suggestion that the global push for interdisciplinarity might be a fad. "The answer is a resounding 'no," he says. "Things have changed - now people focus on big problems, and if you go for a big problem you need to be interdisciplinary." - SEE EDITORIAL P.289

Heidi Ledford writes for Nature from Boston,

Massachusetts. 